\title{
Human Resource Planning Practice in Managing Human Resource: A Literature Review
}

\author{
Hassan Danial Aslam \\ Lecturer, Faculty of Management Sciences, The Islamia University of Bahawalpur (Pakistan) \\ Email: hassan.danial@hrmars.com \\ (Corresponding Author) \\ Mehmood Aslam \\ MS Scholar, Faculty of Management Sciences, The Islamia University of Bahawalpur \\ (Pakistan) \\ Naeem Ali \\ Visiting Faculty, Faculty of Management Sciences, The Islamia University of Bahawalpur \\ (Pakistan) \\ Badar Habib \\ Lecturer, Department of Physical Education, The Islamia University of Bahawalpur \\ (Pakistan)

\section{Madiha Jabeen} \\ MS Scholar, Faculty of Management Sciences, The Islamia University of Bahawalpur \\ (Pakistan) \\ Doi:10.5296/ijhrs.v3i1.6253 URL: http://dx.doi.org/10.5296/ijhrs.v3i1.6253
}

\begin{abstract}
Considered being the first and primary practice of human resource management, human resource planning holds a huge role to play. Theoretical bases of HR planning practices have been investigated in detail in this article. Authors have made an attempt to cover and present comprehensive literature on this important practice of HR. The importance of HR planning, its strategic objectives and factors influencing it are all covered in this literature study. Also, the study covers HR planning frameworks and models and tells the processes to retain and motivate the workforce of the organization.
\end{abstract}

\section{Introduction:}

Keeping in view the concurrent situation, organizations are in search of solutions which not only take them out of perplexing circumstances that are particularly concerned while dealing 
with human resources but also make them come by competitive advantage over others if not more. Human resource planning here comes into play and results in ultimate organizational performance. This review is particularly relates to the overall background research concerning human resource planning. Many eminent academicians and researches came up with their own perspectives while defining human resource planning and its ramifications. Similarly Walker (1980) explained that human resource planning occupies an important role to forecast future demands of business and environmental factors in organization and it also helps to generate and manage the human resource demands as required and as conditions depict.

Human resource planning seems to be in practice by those firms and/or enterprises which consider their employees the most essential part of the organization. Organizations usually become unable to meet the desired objectives just due to the fact that at times of stiff competition, the moral of their employees is not as that good as it is of their counterparts. The reason is quite clear to everyone that the employees of that firm are not having that level of potential or motivation which becomes due while operating at that level in the industry. However, those organizations outperform in the market which does well with the employees in terms of boosting their satisfaction level at work through different ways, motivating them enough to take courage and making them put forth the level best effort to meet the targets.

At times, there are many factors that change the entire way human resource planning is done. Those could be external and internal factors that may influence the whole process of human resource planning like for instance, the external environment and the internal one and open competition in the market, etc. that organization follows and the way through which it aligns the workforce planning with various departmental planning. All these contribute to design different policies and procedures in crafting Human resource planning.

Organizations tend to consistently work on capacity building of their workforce in acute manner and similarly manage the talent of their number of employees in different ways like doing succession planning for best individuals so that they may discharge their responsibility for key positions in future course of time. Therefore, organizations work on numerous ingredients of human resources planning; one of which is that organizations use to streamline the flow of communication across the whole organization which in turn not only boosts the satisfaction of the employees but also adds up significantly to the overall performance of the organization.

The strategic role of human resource planning not only assists the organization in short span of time but also in many times to come. Thus it is being seen that those organization which consider human resource planning as the significant and essential part of their human resource management, this could turn out to be very helpful in terms of dealing with its human capital which could possibly make the organization to standout of the competition prevailing in the market. 
Human Resource Planning:

2013, Vol. 3, No. 1

Human resource planning is generally defined as the process that identifies the number of employees a company requires in terms of high quality and quantity, hence it is seen as an ongoing process of regular and structured planning. The main purpose of human resource planning is to make sure that employees have best level of interaction with their jobs. Also, this planning process confirms that employees are in right number as required i.e. there is neither a surplus of manpower nor a shortage. The three fundamental functions of human resource planning include a) labor forecast, b) managing demand for employees and available supply in market and c) keep a balance between labor supply and demand predictions.

In order to gain competitive advantage over the competitors, Gould (1984) explained that different advantageous ways are found out using strategic human resource functions, thus showing that these functions play a critical role in making a company competitive. Biles et al. (1980) elaborated that organization's ability to achieve strategic objectives is discriminated by its human resource in following three ways: cost economics, capacity for effective operations, ability to take new enterprise and change the operations. Dwevedi (2012) describes "Planning for future balance by comparing the number of employees needed to the number of present employees who can be expected to stay with the organization, a project manager should give more time to the human resources experts to work on that".

Jonathan Rice (2011) stated that Human Resource Planning is a long lasting process organized in a way that properly employs the human resource of the organization. In order to create and maintain the best fit between the job and employee, planning is given special attention. "The three key elements of the HR planning process are forecasting labour demand, analyzing present labour supply, and balancing projected labour demand and supply”.

\section{Influence of human resource planning on organization's performance:}

According to Edwards and Pearce (1988) "Human resource planning is particularly important for emerging, rapid-growth and high tech business. Mature business in need of new products, services, markets, acquisitions or divestitures must also plan to identify, attract or reallocate the talent necessary for revitalization and continued competition". For satisfying training and career development needs of employees and fulfilling organizational demands, succession planning and organization development occupy an important role. If, in case, the in-house supply of labour is more than needed, this problem of resource rearrangement needs to be dealt with.

According to Craft (1980), Human resource planning owns a significant role in deciding and specifying the characteristics of applicants, in order to select the best fit that organization looks for. Noe et al (2003) elaborated that it is important to rightly implement human resource planning in order to create the lead time necessary to confront potential problems 


\section{Al Macrothink \\ International Journal of Human Resource Studies \\ ISSN 2162-3058 \\ 2013, Vol. 3, No. 1}

and threats to the organization's competitive edge.

\section{Impact of human resource planning process on employee performance:}

Organizations take steps for employees' training and development to increase their level of skills and productivity. In a discussion about work force planning, Shantz A. et al. (2009) mentioned that when employees are provided with specific training about their work and job, they can perform better and attentively even if there is no supervision after training takes place. Performance efficiency increases after training. In a study, Marwat A. Zubair et al (2006) have reported seven variables which positively relate with employee performance. Variables include selection, training, performance appraisal, career planning, compensation plans, employee participation and job definition. Sarkodie W.G (2011) has revealed in his thesis study that proper without human resource planning organizations cannot attain their goals. In different organizations, along with employees own different skill sets, abilities and knowledge, organizational resources add to ensure sustained growth and development. Al Ahmadi (2009) emphasized that performance improvement does not result only from good performance of system, rather motivated and committed human resource also plays its part which is possible by successful implementation of human resource strategies.

\section{Planning - A Business Strategy:}

Gould (1984) explained that many factors need attention from human resource professionals and strategists, they must consider all relevant issues, for example if there occurs any mismatch of culture strategies, it can hurt the successful implementation of the course of actions and strategies planned for the future.

According to its operational view, human resource planning investigates all the requirements of the organization and associated needs of management programs, policies and the resources that are necessary to fulfill the requirements. Human resource plans set the bases for all human resource activities. It is commonly taken that human resource planning is the prime activity of the human resource management. Hax (1985) emphasized the important role of human resources strategy by mentioning that for sustaining the firm in the long run and achieving long lasting competitive advantage, HR strategy is important to develop and act upon well-coordinated objectives and to make certain effective action plans. It is taken as a critical component of organization's corporate and business level strategies. HR plans are required to be flexible enough so that these are made in accordance with business environment for the long term period, therefore, as far as human resource planning is concerned, it should also be an uninterrupted and continuous process.

\section{Workforce planning:}

Workforce planning is a systematic, well-integrated, disciplined and a continuous process. It is defined as "The human capital which consists of skills and competencies of the people that 
are required to fulfill the strategic goals and objectives of the organization".

Burack (1985) emphasized the significance of workforce planning by calling it a workforce stock. Planning for workforce is a central function of the human resource department because it is the most important and critical task of the overall human resource planning field. Huma resource planning process makes it certain that right number of employees is available at the right place at the right time required by the business. Gould (1984) mentioned in a study that evaluating HR issues help company gain useful insights about which human abilities are required to implement strategies for successful accomplishment of objectives.

Biles et al. (1980) described that developing strategies, deciding mechanism, having appropriate machinery and instrument development are vital elements for success of any business. Workforce planning is important for smooth functioning, some planning strategies include making operational plans, making and following mission of the organization, regularly collecting, processing and analyzing the quantitative data to have a view of company's success rate. In order to deal with critical circumstances and sudden situations, planning process should also look at the availability and use of mechanical capabilities, this makes planning process credible and fruitful. Business plans and human resource information systems are the two main information providing sources for appropriate workforce planning.

\section{Objectives of Human Resource Planning:}

Butler et al (1991) explain that there is an important role of human resource management to create competitive advantage for the organization against the competitors present in the industry.

Manzini (1988) emphasized that all organizational initiatives need an integration with the HR practices for successfully integrating corporate strategies. When all strategic initiatives i.e. growth, better customers service, innovative production methods, improvements in after sale services, mergers, etc. possess an alignment with HR practices and policies of the organization e.g. with organizing, communicating, developing, appraising, and rewarding employees, and keeping an eye on the future capabilities of the organization, the chances of successful and better resulting implementation of strategic plans increase. The HR practices also need to be aligned with objectives of the organization.

Walker (1990) outlined that "Like most organizational practices, however, the effectiveness of HR planning depends on the perspective within which it is utilized". HR planners need to have clear and precise objectives in mind in order to better execute HR planning process.

Similarly, Ulrich (1987) added that HR planning is recognized as a source of development of organizational functions based on missions and objectives of the business. With the help of planning, areas that need better functioning are identified to make them grow and succeed. "Many HR planning methodologies have been developed and organizations have also crafted 
their own, most of these methods are similar to those described in the literature like: setting up formal objectives, identifying appropriate organizational strategies and searching for any innovative HR applications".

\section{Significance of Human Resource Planning:}

Speamerfam (2011) describes that hiring the best talent for the organization is the job of HR department. Significant amount of planning is required for all this in order to put attractive advertisement to attract talented candidates. Afterwards, job descriptions and job specifications are put forward to provide details relevant to the work, the responsibilities to handle in a particular job, required qualifications, technical and other needed skills. In human resource planning, turnover rate of employees is also forecasted. Lastly, interviews are done and candidates are selected to whom training is provided so that they conduct all their job activities very well. This effective working motivates the employees and reduces the turnover rate of employees. Also, the administrative activities of HR department such as performance appraisal, employee compensation management need proper planning and management of all the functions.

Gopikrishna (2011) also highlighted the significance of human resource planning process by mentioning that objectives of the organization are achieved when planning is done properly. Therefore, organizations at first collect data about the goals and objectives, afterwards it arranges people, resources and other competencies required to meet the objectives.

Dwevedi (2012) defines HRP as a process which helps out in properly performing important HR functions such as true and timely information is provided about when to do recruitment of employees. This timely process saves extra cost of company.

\section{Factors influencing HRP:}

\section{Influence of External Environment on Human Resource Planning:}

"Many factors in the external environment affect human resource planning, including the level of education, the prevailing attitude in society (such as the attitude toward work), many laws and regulations that directly affect staffing, the economic conditions, and the supply of and the demand for managers outside the spectrum of an enterprise. Effective staffing, then, certainly requires recognition of the internal and external situational factors".

\section{Influence of Internal Environment on Human Resource Planning:}

Internal factors influence the concern for dealing with the staffing requirements for managerial positions within and outside the firm, it also shows the staffing needs of employees and responsibility of management. 


\section{Open Competition Policy:}

2013, Vol. 3, No. 1

Under this policy in application, the knowledgeable, skilled and competent employees are identified from inside and outside the organization. Also, competent employees are identified for potential promotions by conducting performance appraisals. Therefore, instead of creating any hindrances in career development of employees, this policy guarantees the productive competition between the employees and promotes advancement of employees.

\section{Linkage and alignment of HR/workforce planning and departmental planning}

John (2008) elaborated that usually a five step process is used for creating a linkage between HR or workforce planning and departmental planning to regulate the current and future requirements and demands of the human resource. These steps include:

1. Determination of business goals.

2. Environmental Scanning (that includes a workforce analysis, and an internal and external scans as well).

3. Performing gap analysis.

4. Deciding HR priorities.

5. To measure, monitor, and report the progress.

To establish HR priorities is the main reason for listing the steps above involved in creating a linkage between HR or workforce planning and departmental and strategic planning.

\section{STEP 1: Determination of business goals:-}

For smooth running of business, organizations need to identify and determine their business goals and prepare government documents including budget speeches and other necessary documents including strategic and business plans (John, 2008). This is important in order to understand governmental regulations, deciding on organization's and department's HR priorities and to cope with changing and new emerging environmental trends.

\section{STEP 2: Environmental Scanning:-}

\section{Analysis of workforce}

John (2008) mentioned that after determining the business goal, next step is to address the need to understand the workforce as well as to plan about the necessary workforce (shortage and surplus) with specific skills and knowledge. There is need to undergo the workforce analysis. Characteristics such as age, gender, skills, competencies, etc. are vital to look at, also some internal factors such as eligibility criteria, vacancy, turnover rate, etc. are significant for conducting workforce analysis. 
Internal scanning

According to John (2008) internal scan mainly looks at identifying the factors that have an effect on the organization's work force capabilities necessary to meet the departmental goals. Barret et al. (2006) mentioned that internal analysis gives attention to workforce trends including their age distribution, and portion of positions filled by internal candidates.

Each department is responsible for identifying the internal opportunities and challenges. It is necessary for the organization to make and retain strengths to face and reduce the risks and challenges to attain success.

\section{External scanning}

Barnard et al. (2006) advised that external analysis should not be a time consuming process. All the potential changes that may occur and their influences may be reviewed by the planning team. Also, team should look at the how the changes impact the organization, its work and recruitment and selection patterns, process of training, retaining and developing the required workforce.

\section{STEP 3: Performing gap analysis:-}

John (2008) explained how to recognize the business goals and requirements and how these may help forecast the future hiring needs, in terms of the number of employees, skills, and work experiences required.

On the basis of departmental goals, priorities and environmental scanning, McGraw-Hill Ryerson (2000) determined the current and future HR requirement. Following questions are found to be helpful in identifying the HR needs and requirements for gap analysis.

1. Do the organization have succession plans for critical positions?

2. In order to bring changes in delivery system, do acquiring new skills necessary?

\section{STEP 4: Deciding HR priorities to help achieve departmental goals:-}

McGraw-Hill Ryerson (2000) explained that after looking at the results of gap analysis, some HR priorities must be decided and strategies to attain the desired outcomes should be developed that must be acknowledged by the department.

STEP 5: Measuring, Monitoring, and Reporting the progress:-

John (2008) mentioned that while evaluating the progress of the targeted area, monitoring, assessing and presenting the results of HR performance is highly critical. It brings improvements in the skills, and capabilities of the employees and organizational learning so as to meet the future needs and demands. 


\section{Macrothink

Developing and Retaining Staff Strategies:

\section{Developing a Talent Pool: Capacity building}

If an organization wants to meet future needs and requirements then the employees must be capable to perform. It would become possible only when the employees are committed to continuous learning and development and are ready to avail the career development opportunities.

Learning and development is not only important to get the competitive benefit but also it is necessary to boost talent and delivery of best services and performances. John (2008) explains that in order to retain the top talent and to deliver the best services there should be access to the learning as well as knowledge and skill enhancement programs by performing the challenging tasks because when challenging tasks are assigned, employees will struggle more and try to find new knowledge related to assigned task. This will enhance their knowledge and skills, and increase their confidence.

\section{Relationship building:}

Providing a significant learning opportunities using a sense of real work is the main ingredient of this activity. For example, organization may consider arranging such programs in different work departments including:

- Apprenticeships

- Internships

- Workshops

- $\quad$ Part time employment

\section{Assignment opportunities:}

Employees get the opportunity to work in the other departments of the organization where the work is different and also there is a need of an employee to complete it. Such opportunities are known as reassignment opportunities. Employers' requirements are also fulfilled this way and also offers at hand learning opportunities to the employees.

Barnard et al. (2006) said that participating in formal succession planning and development programs does not a guarantee employee replacement. Candidates need to face competition on open positions. Succession planning goals may be short term or long term. Following are the factors that measure succession planning:

- Presence of diversified and qualified pool of talent

- Leaders' effectiveness is developed through the process

- The succession planning and the department's workforce planning processes should be integrated. 


\section{Work Environment:}

Work environment is an important factor to consider while developing and implementing staffing strategies. It enhances the level of employee motivation and their satisfaction with the job. Work environment and employee performance are directly related. Quality of performance and commitment enhances if good quality work environment is provided to employees. Also, is reduces absenteeism from and job stress (Lowe et al., 2002).

\section{Leadership:}

Leadership is considered a crucial feature of organizational performance. Employee performance enhances if appropriate leadership is practiced, the behavior of leader is motivational factor which leads employees to work best and make leaders get the best performance from the employees. Intellectual leadership make leaders do the best efforts in company's favor, do their duty ethically as they visualize the future outcomes of their work. Integration between employees working patterns and achievement of team goal is the result of good governance and effective leadership efforts.

Some people opine that effective leadership positively influence the performance of company. It is the result of high performance of employees that the overall performance of the organization enhances and the goals are achieved in their due time. In last fifty years, many leadership theories have been put forward that are found to have an influence on the effectiveness of the organizations where they were employed. It is very important in this age of global competition between the businesses that organizations use such leadership styles that best enable organizations to cope with the dynamic nature of environment. Many researchers have acknowledged that employee performance and leadership are directly related and if leadership phenomenon is ignored, companies suffer with bad results (Oluseyi et al., 2009).

\section{Communication:}

The transfer of messages or information between employees is known as communication. Job satisfaction of workers is strongly influenced by the level and way of communication between the employees. Effective communication, an important and necessary element of the organizational environment, results in informed employees about the challenges of the industry, i.e. what is happening in the industry and at workplace and what is the firm's strategic intent. To make employees able to communicate their concerns, needs and frustrating matter, is the duty of management of the firm by providing support systems. Proper strategic work needs to be done for this purpose. Job satisfaction and openness are directly related as identified in many studies on communication (Tourani et al., 2012). Effective communication in the organization also makes a significant addition in implementating organizations' strategic plans (Ince et al., 2011). 
Organizational effectiveness:

\section{Structure, process and position description:}

For smooth performance of business practices and processes and for describing work positions, organizational structures are developed. These structures guarantee the effective application of the departmental programs and services. The structures are established to organize work into smaller units, teams, divisions, branches, sectors and departments etc.

Also, business practices are designed in an effective manner to get maximum efficiency and effectiveness from strategy implementation in different programs and departments.

Descriptions are added as well to recognize and clarify the roles and responsibilities of workers. Under sound human resource practices, decisions about organization's mission, the design of work and business practices are taken.

Diversity in information and communication technologies have changed the way organizations are structured and managed. De-layering the hierarchies, creating team-based networks and multidisciplinary approaches, shift from a narrow to a broad-based mindset, more attention towards alliances and partnerships, creating interdependent units rather than designing independent activities and horizontal organizational structures that are more elastic and responsive in service delivery are some of the key new design elements of communication structure. The results of better organizational design and business processes contain faster response time, larger spans of control and an increased range of assignments and roles, which is good to enhance employee engagement and productivity (Jhon, 2008).

\section{Development and integration of talent management program:}

Talent management is not only about attracting and retaining the talent. But is also aims at conducting research and development activities, implementing a range of human resource initiatives and working to manage these initiatives. Important and critical problems of human resource management are solved by integrating talent management programs with them. Internal talent pool of current employees is created by talent management programs and activities and it also helps to attract external talent pool of capable candidates. Along with the compensation, many other factors influence this attraction and retention process. This process gives the benefits as well which are:

- Enhanced employee productivity

- Supports effective planning of workforce

- offers career development and management programs to employees

- Supports the work engagement efforts of employees.

- Results in talent development and making talent sources accessible to the organization that can be trusted when necessary (Jhon, 2008).

\section{Uses of HRP process:}


HRP is possibly one of the most critical elements that link the work of the human resources in achievement of business objectives of the organization. It is significant to note that few aspects of human resource management give results for strategic plans and activities (Richard G., 1984). Particularly, human resource policies from human resource planning are required for other areas' policy development and implementation. For this, integration of human resource planning activities and strategic planning is required (kochan et al., 1985).

It is evident that human resource planning is gaining importance in the business community. Because of inflation and weak economic conditions, profits are shrinking, effective human resource planning process is considered much important to enhance production without wastage and with minimum staff requirements to save costs (Georg et al., 1980).

\section{References:}

Azadeh Tourani, Sedegh R, " $2^{\text {nd }}$ International Conference on Economics Trade and Development (IPEDR)” Vol. 36 (2002).

Burack, E. H. (June 1985). "Linking Corporate Business and Human Resource Planning: Strategic Issues and Concerns,” Human Resource Planning. PP.134.

Butler, J. E. Ferris. G. R. and Napier, N. K. (1991). Strategy and Human Resource Management, Cincinnati: South-Western Publishing Co.

Baired et al (1983) Human resource practices and organizational performance: review synthesis and research implications.

Biles, G. E. and Holmberg, S.R. (1980). Strategic Human Resource Planning. Glenn Ridge, New Jersey: Thomas Horton and Daughters. P78.

Butler, J. E. Ferris. G. R. and Napier, N. K. (1991). Strategy and Human Resource Management, Cincinnati: South-Western Publishing Co.

Barnard, W. (2006) "seven steps of effective workforce planning”.

Barrett, K., Richard, G. (2006) "seven steps of effective workforce planning" "When Boomers retire," Governing Magazine.

Craft (1980) Human resource practices and organizational performance: review synthesis and research implications.

Edwards, G., Pearce, E. (1988 to 2000). "Inevitable Forces for Change in America". 
Graham S. Lowe, Grant Schellenberg, Harry S. Shannon (2002).

Gould, R. (1984). "Gaining a Competitive Edge through Human Resource Strategies: Human Resource Planning.

Gould, R. (1984), "Gaining a Competitive Edge through Human Resource Strategies," Human Resource Planning, P.31.

Hax, A., C. (June 1985), "A Methodology for the Development of a Human Resource Strategy," Sloan School of Management, P9.

Mehnet Ince, Hassan Gul, “European Journal of Social Sciences”, volume 21, Number 1 (2011).

Manzini, A. O. (1988). Integrating human resource planning and development: the unification of strategic, operational, and human resource planning systems'. Human Resource Planning, Vol. 11, 79-94.

Noe et al (2003) Human resource practices and organizational performance: review synthesis and research implications.

Odiorne, G., S. (Nov/Dec 1984), "Human Resources Strategies for the Nineties," Personnel, P14.

Speamerfam, G. (2011) "What is human resource planning and the level of importance to an organization"?

St. J.. (2008). Human Resource Planning: New Found land Labrador.

Shadare Duseyi A., Hammed, t. Ayo (2009).

Ulrich, D. (1987). 'Strategic human resource planning: why and how?' Human Resource Planning, Vol. 10, no. 1, 37-56.

Walker, J. W. (1990).'Human resource planning, 1990 style'. Human Resource Planning, Vol. 13, no. 4, 229-240.

Weihrich, H., Koontz, H., Donnell, C. O., (1980).New York: McGraw-Hill Book Company, 7th edition. 